\title{
Kablosuz Algılayıcı Ağlarda En Az Sayıda Düğüm Kullanımı için Maliyet Etkin Algılayıcı Düğüm Yerleştirme Yaklaşımı
}

\section{Cost Efficient Sensor Node Placement Approach for Using Minimum Number of Node in Wireless Sensor Networks}

\author{
Geliş / Received: 17/05/2019
}

\author{
Muhammed Enes Bayrakdar ${ }^{1 *}$
}

Revize / Revised: 02/07/2019

Kabul / Accepted: 04/07/2019

z- Kablosuz algılayıcı ağlar birçok alanda yaygın olarak kullanılan kablosuz ă̆ teknolojisidir. Yeraltı, karasal, sualtı ve endüstriyel algılayıcı ağlar olmak üzere farklı kullanım alanları bulunmaktadır. Kablosuz algılayıcı ağlardaki en önemli sorunlardan birisi, algılayıcı düğümlerin mekanik nedenlerden dolayı arızaya meyilli olmasıdır. Diğer bir sorun ise, kablosuz algılayıcı düğümlerin sınırlı enerjiye sahip olmasıdır. Bu bağlamda, hata sezme mekanizmaları bulunan ve enerji verimli olarak çalışan algılayıcı ağ tasarımları büyük önem taşımaktadır. Bunun yanında, maliyet açısından algılayıcı düğümlerin yerleştirildiği konumları belirleme tekniği oldukça önemlidir. Düğümlerin yerleştirildiği konumlar, hedef bölgenin bir düğümün algılama alanı içinde olma olasılığını ve bu düğümün baz istasyonu ile olan bağlantısını etkilemektedir. Bu makale çalışmasında, çok sayıda algılayıcı düğümün geniş bir alana yerleştirildiği farkı bir yaklaşım önerilmektedir. Algılayıcı düğümler; belirli bir bölgedeki sıcaklık, nem, basınç vb. parametreleri algılamak için tüm bölgeyi kapsayacak şekilde yerleştirilmektedir. Düğümler tarafından algılanan değerler, merkezde sabit olarak bulunan baz istasyonu tarafından toplanmaktadır. Önerilen yaklaşımın benzetim modeli, Riverbed Modeler yazılımı kullanılarak gerçekleştirilmiştir. Önerilen yaklaşım sayesinde, belirli bir bölgenin en az sayıda kablosuz algılayıcı düğüm ile sezilmesi sağlanmaktadır.

Anahtar Kelimeler- Cihaz Maliyeti; Düğüm Yerleştirme; Enerji Tüketimi; Kablosuz Algılayıcı Ăğ Kapsama Alanı

\begin{abstract}
A bstract- Wireless sensor networks are widely used wireless network technology in many areas. There are different usage areas such as underground, terrestrial, underwater and industrial sensor networks. One of the most important problems in wireless sensor networks is that the sensor nodes are prone to malfunction due to mechanical reasons. Another problem is that the wireless sensor nodes have limited energy. In this context, sensor network designs with error sensing mechanisms and energy efficient operations are of great importance. In addition, the technique of determining the locations where the sensor nodes are placed is very important in terms of cost. The locations where the nodes are placed affect the probability that the target region is within the detection area of a node and its connection with the base station. In this paper, a different approach is proposed in which a large number of sensor nodes are placed on a large area. Sensor nodes are placed to cover the entire region in a specific area in order to detect the parameters such as temperature, humidity, pressure, etc. The values detected by the nodes are collected by the base station which is fixed at the center. The simulation model of the proposed approach was performed by using Riverbed Modeler software. Thanks to the proposed approach, it is ensured that a certain region is sensed by the minimum number of wireless sensor nodes.
\end{abstract}

Keywords- Device Cost; Node Placement; Energy Consumption; Wireless Sensor Network; Coverage Area

1*Sorumlu yazar iletişim: muhammedbayrakdar@duzce.edu.tr (https://orcid.org/0000-0001-9446-0988)
Bilgisayar Mühendisliği Bölümü, Düzce Üniversitesi, Merkez, Düzce 


\section{GİRIŞ}

Kablosuz algılayıcı ağlar, potansiyel olarak algılama yetenekleri ve kablosuz iletişim bağlantıları olan çok sayıda cihazdan oluşmaktadır. Kablosuz algılayıcı ağlar, nispeten düşük maliyetleri sebebiyle son zamanlarda tıbbi izleme, trafik denetlemesi, çevresel risk takibi ve felaketlerin tespit edilmesi gibi alanlarda yaygın olarak kullanılmaktadır.

Kablosuz algılayıcı cihaz fiyatlarındaki düşüşe rağmen, yüz binlerce algılayıcı düğüm kullanımı gerektiren uygulamalar için algılayıcı ağların maliyeti oldukça yüksek olabilmektedir. Çok fazla algılayıcı düğüm cihaz gerektiren bu tür uygulamalarda algılayıcı dügümlerin konumu kritik öneme sahiptir. Bunun sebebi, algılayıcı sayısının kablosuz algılayıcı ağlarda hem maliyeti hem de performansını etkilemesidir. Bu nedenle, düğüm yerleşimi için kullanılabilecek makul uygulama sürelerine sahip verimli algoritmalara ihtiyaç duyulmaktadır. Düğüm yerleşiminde karşılanması gereken temel özellikler; algılayıcı sayısını en aza indirmek, kapsama gereksinimlerini karşılamak ve çok büyük ağlar için algılayıcı düğüm dağılımını hesaplamaktır.

Algılayıcı düğümler izleme yapılacak alanın yapısına ve doğasına göre genel olarak rasgele veya deterministik olarak yerleştirilmektedirler. İzleme yapılacak bölgenin özellikleri bilinmiyorsa veya bölge erişilebilir değil ise rasgele dağılım kullanılmaktadır. Rasgele dağılım kullanıldığında, algılayıcı sayısını en aza indiren sistematik bir algılayıcı cihaz yerleşim yaklaşımı uygulanamamaktadır. Diğer taraftan; bölge erişilebilir olduğunda ve bölgenin özellikleri iyi bilindiğinde, algılayıcı düğümlerin belirli konumlarda deterministik olarak konuşlandırması yaklaşımı kullanılabilmektedir.

Kablosuz algılayıcı ağlar, günümüzde her alanda yaygın bir şekilde kullanıldığından farklı amaçlar için üretilen çok sayıda algılayıcı düğüm bulunmaktadır. Bu çalışmanın motivasyonu, birçok farklı alan ve ortam koşullarında kullanılan algılayıcı düğümlerin en uygun şekilde yerleştirilmesine yönelik yeni bir yaklaşım önermektir. Önerilen yaklaşımın amacı, belirli bir alanı en az sayıda algılayıcı düğüm ile kapsayarak düğüm maliyetinden tasarruf etmektir.

Bu makale çalışmasını ortaya çıkaran nedenler şu şekilde sıralanmaktadır: (i) Kablosuz algılayıcı ağların günümüzde yeraltı, sualtı, karasal ve endüstriyel alanlarda yaygın olarak kullanılması. (ii) Kablosuz algılayıcı düğümlerin mekanik ve teknik sebeplerden dolayı arızalanması. (iii) Çok sayıda kablosuz algılayıcı düğüm kullanımı gereken durumlarda, maliyeti düşürmek için en az sayıda kablosuz algılayıcı düğüm kullanımı gerekliliği. (iv) En az sayıda kablosuz algılayıcı düğüm kullanımı için maliyet etkin düğüm yerleştirme yaklaşımı gerekliliği.

Bu makale çalışmasının katkıları şu şekilde sıralanmaktadır: (i) Belirli bir bölgenin en az sayıda kablosuz algılayıcı düğüm ile sezilmesinin sağlanması. (ii) En az sayıda algılayıcı düğüm kullanarak, maliyetin mümkün olan en düşük seviyeye indirilmesi. (iii) Kablosuz algılayıcı ağın toplam enerji tüketiminin en aza düşürülmesi. (iv) Riverbed Modeler yazılımı kullanılarak kablosuz algılayıcı ağ benzetim modelinin yapılması. (v) Kablosuz algılayıcı ağlar için düğüm yerleştirme yaklaşımlarının matematiksel olarak hesaplanması. (vi) Düğüm yerleştirme yaklaşımlarında kullanılması gereken algılayıcı düğüm sayılarının tablo yardımıyla karşılaştırılması. (vii) Önerilen düğüm yerleştirme yaklaşımının, diğer iki yaklaşımdan daha iyi sonuçlar verdiğinin tablo ve grafik sonuçları ile ortaya konulmas1.

$\mathrm{Bu}$ makale çalışmasında, kablosuz algılayıcı düğümlerin belirli bir konuma deterministik olarak yerleştirilmesi için farklı bir yaklaşım önerilmektedir. Bu yaklaşıma göre, düşük maliyetli kablosuz algılayıcı ağ yapısı kurmak için en az sayıda düğüm kullanımı ve düğümler arasındaki mesafe dikkate alınmaktadır. Her bir algılayıcı düğümün algılama alanı ve düğümler arası mesafe göz önüne alındığında, önerilen yaklaşımın en az sayıda düğüm kullanımını garanti ettiği net bir şekilde gösterilmektedir.

\section{II. İLGILII ÇALIȘMALAR}

Kablosuz algılayıcı ağlarda, düğüm yerleştirme ile ilgili olarak yapılan çeşitli çalışmalar bulunmaktadır. Düğümlerin mümkün olan en uygun konumlara yerleştirilmeleri maliyet ve enerji tüketimi açısından oldukça önemlidir. Tang ve diğg., röle düğümü yerleştirme problemini büyük ölçekli kablosuz algılayıcı ağlarda incelemişlerdir [1]. Liu ve diğ., iki katmanlı kablosuz algılayıcı ağlarda röle düğümü yerleştirme sorununu çözmüşlerdir [2]. Lloyd ve Xue, algılayıcı düğümlerin $r>0$ ve röle düğümlerin $R>=r$ iletişim aralığına sahip olduğunu varsaymışlardır ve röle düğümü yerleştirme probleminin iki farklı sürümünü incelemişlerdir [3]. Yaptıkları çalışmada, $\mathrm{r}$ algılayıcı düğüm kapsama alanını ve R röle düğüm kapsama alanını temsil etmektedir [3]. 
Ishizuka ve Aida, pek çok algılayıcı düğümün geniş bir alana yerleştirildiğinde, etkin bir yaklaşımın olasılıklı düğüm yerleşimi olduğunu vurgulamışlardır [4]. Bu sayede, algılayıcıların kontrollü bir şekilde dağılarak yaklaşık konumlarının bir olasılık yoğunluk fonksiyonu ile nitelendirilebileceğini düşünmüşlerdir [4].

Younis ve Akkaya, kablosuz algılayıcı ağlarda optimize edilmiş düğüm yerleşimi üzerine yapılan araştırmaların mevcut durumu hakkında inceleme yapmışlardır [5]. Hu ve diğ., potansiyel olarak çok sayıda hareketli algılayıcıdan ve bilgi toplama için tek veya çok sayıda sabit hedef düğümden oluşan hareketli algılayıcı ağ mimarisi sunmuşlardır [6]. Pandey ve diğ., kümeleme kavramını kullanan iki katmanlı hiyerarşik heterojen kablosuz algılayıcı ağ yapısını ele almışlardır [7]. Misra ve diğ., röle düğümlerin yalnızca bir dizi aday konuma yerleştirilebileceği, röle düğümü yerleştirme probleminin kısıt içeren versiyonunu incelemişlerdir [8].

Hou ve diğ., mevcut bir ağın kapsamını iyileştirmek için yeni eklenen algılayıcıların en iyi şekilde nasıl dağıtılacağını incelemişlerdir [9]. Han ve diğ., algılayıcı düğümlerin farklı iletim yarıçaplarına sahip olduğu heterojen kablosuz algılayıcı ağlarda, daha yüksek ağ bağlantısına sahip hata toleransı sağlamak için röle düğümlerin dağıtılması sorununu ele almışlardır [10]. Lu ve diğ., sınırlı bir düzlemde röle düğümü yerleştirme probleminin bir P problemi olduğunu ancak genel durumdaki hesaplama karmaşıklığının oldukça büyük olduğunu kanıtlamışlardır [11]. Liang ve diğ., yoğun bir algılayıcı ağda veri toplama işlemi sırasında ağın kullanım ömrünün önemli ölçüde uzaması için ekstra güçlü küme düğümleri yerleştirilen algılayıcı ağ tasarımını ele almışlardır [12].

Lee ve Younis, en az sayıda röle düğümü kullanarak bölümlenmiş kümeler arasında bağlantı kurmak için etkili bir strateji önermişlerdir [13]. Chen ve Li, sırasıyla tek ve çok atlamalı kablosuz algılayıcı ağlarda enerji ve yaşam süresi odaklı hedef düğüm yerleştirme stratejilerini araştırmışlardır [14]. Tapiador ve Clark, düğüm yerleşim problemini formül haline getirerek hem teorik hem de deneysel olarak çalışmışlardır [15]. Kimence ve Bekmezci, ağırlıklı bir arazi yapısında kablosuz algılayıcı ağ bağlantısı sağlamak için röle düğümü yerleştirme problemini araştırmışlardır [16].

Wu ve diğ., kablosuz algılayıcı ağlarda yeraltı boru hattı incelemesi için yer üstü röle düğümlerin yerleştirilmesinde kullanılan kanal tabanlı bir metodoloji sunmuşlardır [17]. Ranga ve diğ., kablosuz algılayıcı ağlardaki ă̆ bölümleme sorununu iyileştirmek için yeni bir çözüm önermişlerdir [18]. Ma ve diğ., sistemin genel olarak tasarruflu bir şekilde çalışması amacıyla, kablosuz algılayıcı ağlarda röle düğümü yerleşimi için yeni bir bağlantı duyarlı yaklaşım algoritması önermişlerdir [19]. Vikrant ve diğ., algılayıcı düğümlerin büyük ölçekli bir hedef bölgede hızlı ve hassas bir şekilde konuşlandırılması için otomatik bir mekanizma önermişlerdir [20].

Bagaa ve diğ., sınırlı sayıda konum verilen kablosuz algılayıcı ağlarda röle düğümlerini en uygun şekilde yerleştirme problemini ele almışlardır [21]. Njoya ve diğ., hem verimli (azaltılmış sayıda algılayıcı ile tam kapsama alanı) hem de ölçeklendirilebilir (makul bir hesaplama süresinde çok büyük ölçekli problemler için uygulanabilirlik) yeni bir olasılık-fizik tabanlı optimizasyon algoritması önermişlerdir ve uygulamışlardır [22]. Chang ve diğ., çıkmaza duyarlı robot dağıtım algoritması önermişlerdir [23]. Cheng ve diğ., veri havuzundaki sıcak nokta sorununu azaltarak, algılayıcı ağ ömrünü en üst düzeye çıkaran dağıtım stratejilerini araştırmışlardır [24]. Akyildiz ve diğ., mikro-elektromekanik sistemler teknolojisi, kablosuz iletişim ve dijital elektroniğin bir arada kullanımıyla uygulanabilir hale getirilmiş olan algılayıcı ağlar konusunu ele almışlardır [25]. Vuran ve diğg., gelişmiş etkili iletişim protokollerinin gerçekleştirilmesi amacıyla kablosuz algılayıcı ağlardaki korelasyonu yakalamak ve kullanmak için birkaç temel unsur araştırmışlardır [26].

Soman ve diğ., basit bir alüminyum plakada kullanılmak üzere genetik algoritma tabanlı optimizasyon stratejisi önermişlerdir [27]. Demetri ve diğ., en iyi düğüm yerleşimini otomatik olarak ve dağıtımdan önce tanımlamak amacıyla uzaktan algılamayı kullanan bir yaklaşım olan kablosuz algılayıcı ağlar için havadan 1şık algılama destekli yerleştirme yaklaşımını (LaPS) sunmuşlardır [28]. Nandy ve diğ., eşzamanlı paralel ada modeline dayanan genetik algoritmayı, ortak algılayıcıların / aktüatörlerin optimum yerleşimlerini aramak için kullanmışlardır [29]. Trothe ve dĭ̆., akıllı binalar için arıza teşhis problemini ele almışlardır [30]. Makalede kullandıkları yöntem Dulmage-Mendelsohn ayrıştırmasını kullanan model tabanlı bir tekniktir. Jo ve diğ., algılayıcıların optimal sayısını ve yerleşimini belirlemek için yanma, akış ve katalizli bir buhar makinesi modeline boşluklu ayrıştırma yöntemi uygulamışlardır [31]. Blachowski tarafından, mekansal truss yapılarının hasar tespiti için kapsamlı bir yaklaşım sunulmuştur [32]. Spinelli ve diğ., belirli bir topluluğa yayılan salgın hastalıkların küçük bir düğüm kümesi tarafından tespit edilmesi için iki boyut içeren genel bir çerçeve önermişlerdir [33].

Literatürdeki kablosuz algılayıcı ağlarda düğüm yerleşim problemini ele alan indeksli makaleler incelendiğinde, doğrudan maliyeti azaltmak amacıyla düğüm sayısını en aza düşürmeyi amaçlayan çalışmalara 
rastlanmamıştır. Bu makale çalışmasının temel amacı, belirli bir alana yerleştirilen düğüm sayısını en aza indirerek maliyetten büyük oranda tasarruf etmeyi sağlayan farklı bir yaklaşım önermektir.

Tablo 1. İlgili çalışmaların karşılaştırılması.

\begin{tabular}{cccc}
\hline Kullanılan yöntem ve teknik & Eksiklikleri & Çalışma ile ilgileri & Kaynak numarası \\
\hline \multirow{2}{*}{ Kapsama alanı } & En az sayıda düğüm kullanımı & Röle düğüm & {$[1],[2],[3],[7],[8]$,} \\
& sağlanamaması & yerleştirme işlemi & {$[10],[11],[13],[16]$,} \\
& En az sayıda düğüm kullanımı & Olasıllı tabanlı düğüm & {$[17],[18],[19],[21]$} \\
Rasgele & sağlanamaması & yerleştirme işlemi & {$[4],[27],[29],[32]$} \\
& En az sayıda düğüm kullanımı & Genel düğüm & {$[5],[9],[12],[15]$,} \\
Kapsama alanı, Rasgele & sağlanamaması & yerleştirme işlemi & {$[20],[22],[23],[24]$,} \\
& En az sayıda düğüm kullanımı & Hedef düğüm & {$[25],[26],[30],[33]$} \\
Kapsama alanı & sağlanamaması & yerleştirme işlemi & {$[6],[14],[28],[31]$} \\
\hline
\end{tabular}

Tablo 1'de, ilgili çalışmaların kullanılan yöntem ve tekniklere göre karşılaştırmalı olarak genel bir özeti verilmektedir.

\section{KABLOSUZ ALGILAYICI AĞLARDA DÜĞÜM YERLEŞTİRME}

Kablosuz algılayıcı ağlarda düğüm yerleştirme işlemi için, öne çıkan iki farklı yöntem bulunmaktadır. Bunlardan ilki, düğümlerin belirli bir alana gelişigüzel bir şekilde dağıtıldığı rasgele düğüm yerleşimi yaklaşımıdır. İkincisi ise, algılayıcı düğümlerin bir bölgeyi tamamen kapsayacak şekilde yerleştirildiği kapsama alanına göre yerleşim yaklaşımıdır. Bu makalede ise, kapsama alanına göre yerleşim işleminin farklı bir türü olan maliyet etkin bir yaklaşım önerilmektedir.

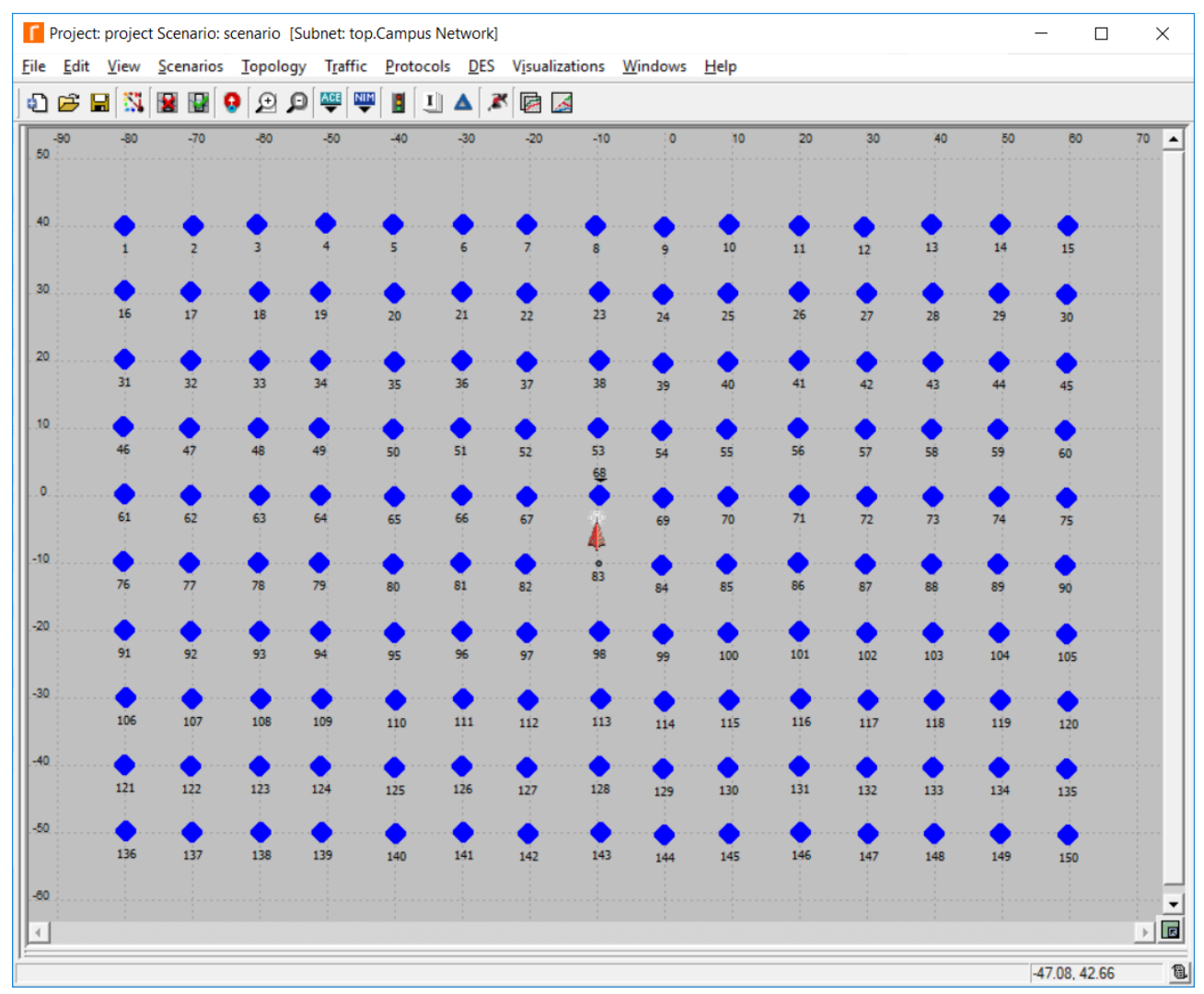

Şekil 1. Riverbed benzetim modeli ağ yapısı. 
Şekil 1'de, Riverbed benzetim modelinde toplam 150 adet algılayıcı düğüm ve baz istasyonu bulunan ağ yapısı görülmektedir.

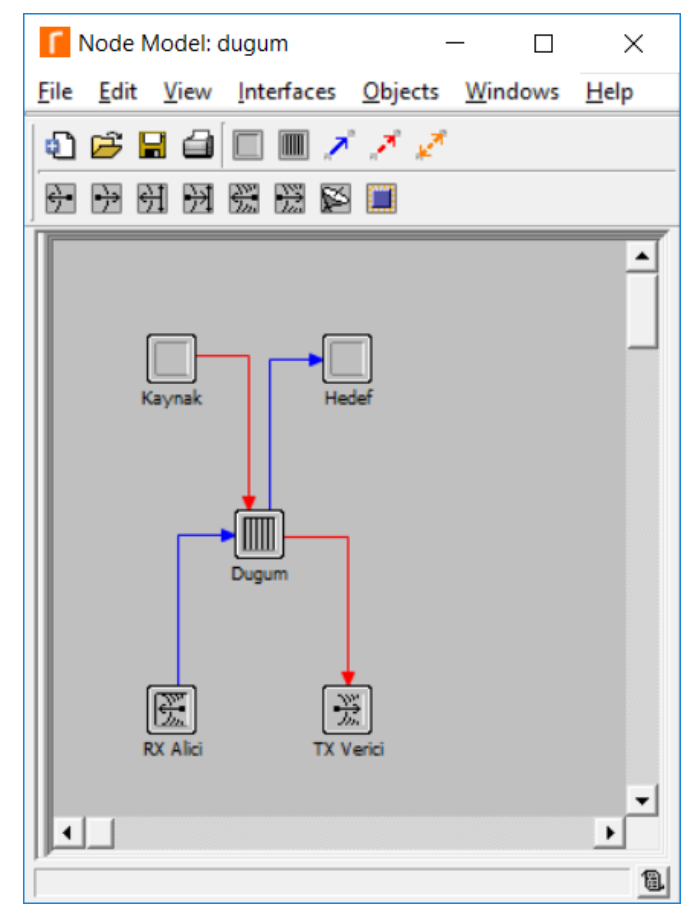

Şekil 2. Riverbed yazılımı algılayıcı düğüm modeli.

Şekil 2'de, Riverbed yazılımı kablosuz algılayıcı düğüm modeli görülmektedir. Kaynak tarafindan üretilen veriler, TX verici yardımıyla doğrudan baz istasyonuna gönderilmekte veya çoklu atlama desteği ile baz istasyonuna iletilmek üzere yakındaki algılayıcı düğümlere gönderilmektedir. Kablosuz algılayıcı ağlar çoklu atlama desteği sunduğundan dolayı, algılayıcı düğümlerin düğüm modeli içerisinde RX alıcı bulunmaktadır. Diğer bir ifadeyle, baz istasyonuna uzak olan algılayıcı düğümler verilerini çoklu atlama desteği sayesinde yakındaki algılayıcı düğümler yardımıyla baz istasyonuna göndermektedir. RX alıcı yardımıyla alınan veriler, hedef işlemine iletilmektedir. Hedef işlemi, gelen verinin kendisine gelip gelmediğini kontrol eder. Gelen veri çoklu atlama desteği ile baz istasyonuna gönderileceği için, hedef işlemi veriyi TX vericiye aktarmaktadır. TX verici de kendisine gelen veriyi doğrudan baz istasyonuna göndermekte veya çoklu atlama desteği ile baz istasyonuna iletilmek üzere yakındaki algılayıcı düğümlere göndermektedir. Çoklu atlama desteği, uzaktaki algılayıcı dügüumler verilerini baz istasyonuna iletene kadar devam etmektedir. Dügüum modeli içerisinde; sezilen veri üretimi, TX vericiye aktarma işlemi, RX alıcıyla alma işlemi ve hedefe aktarma işlemi için gereken kodlar proto C yazılım dili kullanılarak gerçekleştirilmektedir.

\section{A. Rasgele Düğ̈̈̈m Yerleşimi}

Rasgele düğüm yerleşimi, çok sayıda kablosuz algılayıcı düğümün belirli bir alana gelişigüzel bir şekilde yerleştirilmesi olarak ifade edilmektedir. Genel olarak, ulaşılması zor olan konumlara bu şekilde düğüm yerleştirme işlemi yapılmaktadır. Bu yerleşim şeklinin avantajı, ön kurulum ve hesaplama gerektirmemesidir. Dezavantajları ise; tüm alanın aralıksız olarak net bir şekilde sezilememesi, gereğinden fazla kablosuz algılayıcı düğüm kullanımı ve aynı konumun lüzumsuzca birden fazla algılayıcı düğüm tarafından sezilmesi olarak karşımıza çıkmaktadır. Görüldüğü üzere, bu yerleşim yönteminin dezavantajları avantajından çok daha maliyetli olmaktadir. 


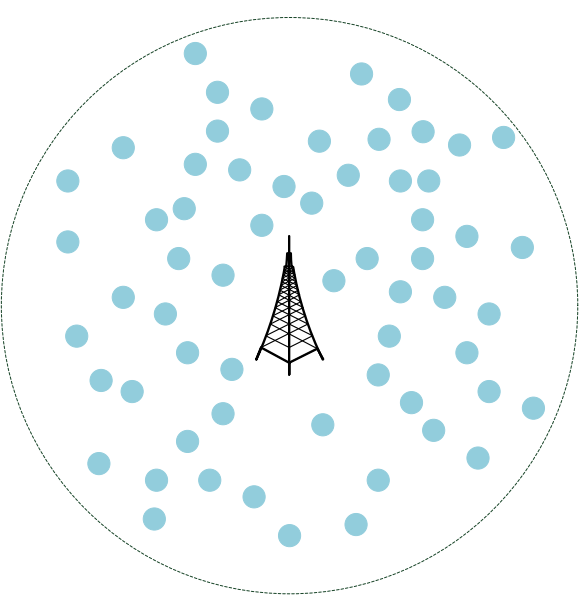

Şekil 3. Rasgele düğüm yerleşimi.

Şekil 3’te rasgele düğüm yerleşiminin gerçekleştirildiği benzetim senaryosu görülmektedir. Bu senaryo, çok sayıda algılayıcı düğüm ve bir tane baz istasyonu kullanılarak tasarlanmıştır. Algılayıcı düğümler, ortamdan sezdikleri nem, sıcaklık, basınç, vb. verileri baz istasyonuna iletmektedirler. Tüm sezilen veriler, baz istasyonunda toplanmaktadır.

\section{B. Kapsama Alanina göre Düğ̈̈m Yerleşimi}

Kapsama alanına göre düğüm yerleşimi, belirli bir bölgenin tüm algılayıcı düğümler tarafından aralıksız olarak sezildiği düğüm yerleştirme yöntemidir. Bu yöntemde, kablosuz algılayıcı düğümler tüm alanı sezecek şekilde özenle yerleştirilmektedir. Şekil 4'te, kapsama alanına göre dügüm yerleşiminin benzetim senaryosu görülmektedir. Benzetim senaryosu, çok sayıda algılayıcı düğüm ve baz istasyonundan oluşmaktadır. Kablosuz algılayıcı düğümlerin kapsama alanı kırmızı kesikli çizgilerle gösterilmektedir. Boşta sezilmeyen alan kalmayacak şekilde yerleştirilen düğümler, sezdikleri verileri baz istasyonuna iletmektedirler. Baz istasyonu, kapsama alanı içinde sezilen tüm verileri algılayıcı düğümler yardımıyla toplamaktadır.

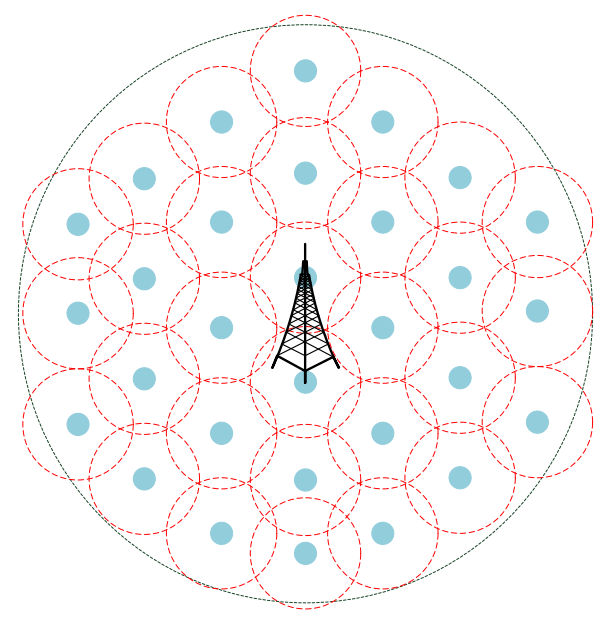

Şekil 4. Kapsama alanına göre düğüm yerleşimi.

Kapsama alanına göre yerleştirme yönteminin avantajları; tüm alanın aralıksız olarak sezilmesi ve makul sayıda algılayıcı düğüm kullanımı olarak karşımıza çıkmaktadır. Bu sayede, algılayıcı düğüm sayısından ve maliyetinden tasarruf edilmektedir. Dezavantajı ise, düğ̈̈mlerin kapsama alanında bulunan kesişim noktalarının gereksiz olarak birden fazla düğüm tarafından sezilmesidir. 
Şekil 5’te, kapsama alanına göre düğüm yerleşiminde düğümler arası mesafe gösterilmektedir. Düğümler arasındaki mesafe siyah çizgiler ile gösterilmekte olup, düğümlerin yerleşimi bu mesafeler dikkate alınarak yapılmaktadır.

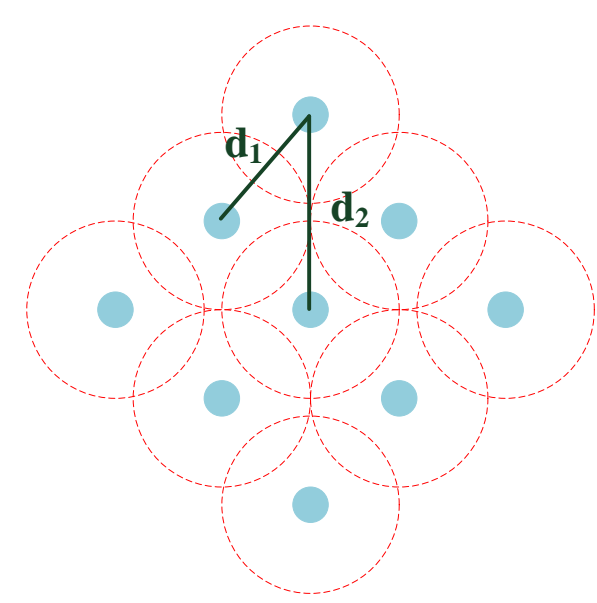

Şekil 5. Kapsama alanına göre yerleşimde dügümmler arası mesafe.

Düğümler arası mesafe hesabı, Şekil 3 'te siyah çizgi ile görülen iki farklı uzunluk hesaba katılarak yapılmaktadır. Bu mesafelerden kısa olan $\mathrm{d}_{1}$ ve uzun olan $\mathrm{d}_{2}$ olmak üzere (1) ve (2) yardımıyla hesaplanmaktadır.

$$
\mathrm{d}_{1}=(\mathrm{r}-\lambda)+(\mathrm{r}-\lambda)
$$

Denklem (1)'de; $\mathrm{d}_{1}$ kısa olan düğümler arası mesafeyi, $\mathrm{r}$ bir düğümün kapsama alanının yarıçapını ve $\lambda$ kapsama alanlarının kesiştiği yaklaşık uzunluğu göstermektedir.

$$
\mathrm{d}_{2}=(\mathrm{r}+\lambda)+(\mathrm{r}+\lambda)
$$

Denklem (2)'de; $d_{2}$ uzun olan düğümler arası mesafeyi, $r$ bir düğümün kapsama alanının yarıçapını ve $\lambda$ kapsama alanları arasında kalan boşluğun yaklaşık uzunluğunu göstermektedir.

\section{C. Önerilen Düğüm Yerleştirme Yaklaşımı}

Önerilen düğüm yerleştirme yaklaşımı, belirli bir alanı kısmen aralıksız olarak en az sayıda düğüm ile sezmeyi amaçlayan yeni bir yöntemdir. Belirli bir alanı en az sayıda algılayıcı düğüm ile sezmek, aynı zamanda önerilen yaklaşımın maliyet etkin bir yöntem olduğunu göstermektedir. Kapsama alanına göre düğüm yerleştirme yaklaşımına benzer şekilde çalışmasına rağmen, önerilen yaklaşımda kesişim bölgeleri ortadan kaldırılmaktadır. Kesişim bölgelerinin ortadan kaldırılmasıyla, aynı alan daha az sayıda algılayıcı düğüm ile sezilmektedir. Düğümlerin kapsama alanı dışında kalan küçük bölgeler; sıcaklık, nem, basınç, vb. değerlerin sonuçlarını çok fazla etkilememektedir. Sıcaklık, nem ve basınç algılayıcılarının maliyetleri sırasıyla; 15 TL, 14 TL ve 13 TL olmaktadır. Kullanılan düğüm sayısına göre güncel fiyatlar üzerinden hesaplama yapılabilmektedir. 


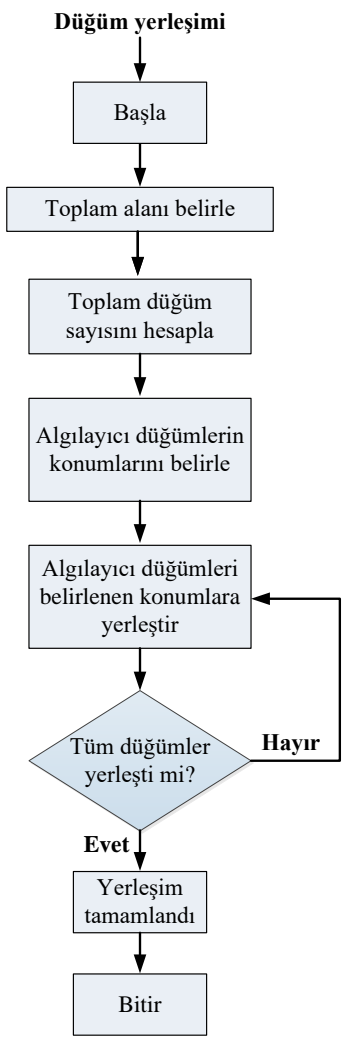

Şekil 6. Önerilen yaklaşımın akış şeması.

Şekil 6'da önerilen yaklaşımın akış şeması verilmektedir. Önerilen düğüm yerleştirme yönteminin avantajları; tüm alanın kısmen aralıksız olarak sezilmesi, en az sayıda algılayıcı düğüm kullanımı ve kapsama alanı kesişim bölgelerinin ortadan kaldırılması olarak karşımıza çıkmaktadır. Bu sayede, algılayıcı düğüm sayısından ve maliyetinden en yüksek seviyede tasarruf edilmektedir.

Şekil 7'de, önerilen yaklaşıma göre düğümler arası mesafe görülmektedir. Düğümler arası mesafe siyah çizgi ile gösterilmektedir. Tüm düğümlerin birbirlerine olan uzaklıkları eşit olmaktadır. X ile gösterilen alanlar, kapsama alanları dışında kalan ve ihmal edilebilecek kadar küçük olan bölgelerdir. X ile gösterilen bölgelerin alanı, r bir algılayıcı düğümün kapsama alanının yarıçapı olmak üzere (3)'deki gibi hesaplanmaktadır.

$$
X=\frac{r^{2}(2 \sqrt{3}-\pi)}{2}
$$

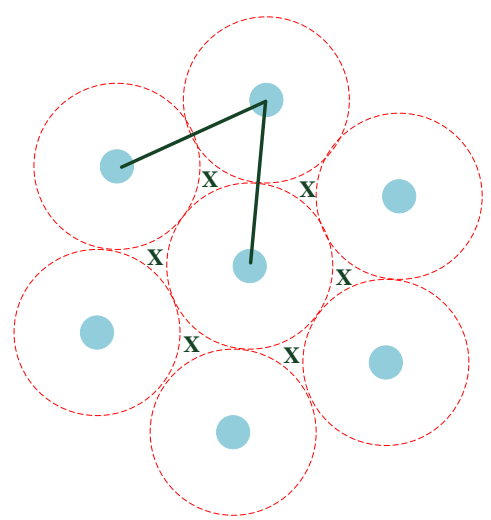

Şekil 7. Önerilen yaklaşıma göre düğümler arası mesafe. 
Önerilen yaklaşıma göre kablosuz algılayıcı düğümler arası mesafe d olmak üzere, (4)'deki gibi hesaplanmaktadır.

$$
d=(r+r)
$$

Denklem (4)’te; d algılayıcı düğümler arası mesafeyi ve r bir algılayıcı düğümün kapsama alanının yarıçapını göstermektedir.

\section{GRAFIKSEL BULGULAR}

Elde edilen sonuçları değerlendirmek amacıyla; toplam harcanan enerji, algılayıcı düğüm sayısı, benzetim süresi, kapsama alanı ve iş çıkarma oranı (throughput) parametreleri incelenmiştir. Toplam harcanan enerji, belirli bir zamanda algılayıcı düğümlerin harcadığı toplam enerjiyi ifade etmektedir. Algılayıcı düğüm sayısı, ağ yapısında belirli bir zamanda bulunan toplam algılayıcı düğüm sayısını göstermektedir. Benzetim süresi, benzetimin başından sonuna kadar geçen süreyi temsil etmektedir. Kapsama alanı, algılayıcı düğümlerin veri sezme işlemini gerçekleştirdiği alanı belirtmektedir. İş çıkarma oranı ise; kablosuz algılayıcı ağ üzerinde baz istasyonuna başarılı bir şekilde iletilen veri miktarının, toplam üretilen veri miktarına oranı olarak ifade edilmektedir.

Tablo 2. Benzetim modelinde algılayıcı düğümler için parametreler ve değerleri.

\begin{tabular}{lc}
\hline İlgili Parametre & Parametre Değeri \\
\hline Modülasyon tekniği & BPSK \\
Veri oranı & $1 \mathrm{Mbps}$ \\
Gecikme & $5 \mu \mathrm{s}$ \\
İletim gücü & $20 \mathrm{~mW}$ \\
Anten kazancı & $2 \mathrm{~dB}$ \\
Benzetim süresi & $3600 \mathrm{~s}$ \\
Kapsama alanı & $\sim 5 \mathrm{~m}^{2}$ \\
Ortam erişim tekniği & Slotted ALOHA \\
Yol kaybı modeli (Teorik) & Serbest uzay yol kayb1 \\
Yol kaybı modeli (Gerçek ortam) & Log normal gölgeleme \\
Yol kaybı katsayısı, $\gamma($ Gerçek ortam) & 3,7 \\
Standart sapma, $\sigma$ - (Gerçek ortam) & $6,4 \mathrm{~dB}$ \\
Varyans, $X_{\sigma}$ - (Gerçek ortam) & $13,6 \mathrm{~dB}$ \\
Frekans & $2,4 \mathrm{Ghz}$ \\
\hline
\end{tabular}

Kablosuz algılayıcı ağ düğüm yerleştirme işlemleri için Riverbed Modeler benzetim yazılımı kullanılmıştır [34]. Benzetim modelinde algılayıcı düğümler için kullanılan parametreler ve değerleri Tablo 2'de verilmektedir. Riverbed Modeler, kablosuz iletişim ağlarının modellenmesi için kullanılan kapsamlı bir benzetim modeli geliştirme ortamıdır. Benzetim modelinin performans değerlendirmesi, ayrık olay benzetimleri aracılığıyla gerçekleştirilmektedir. 


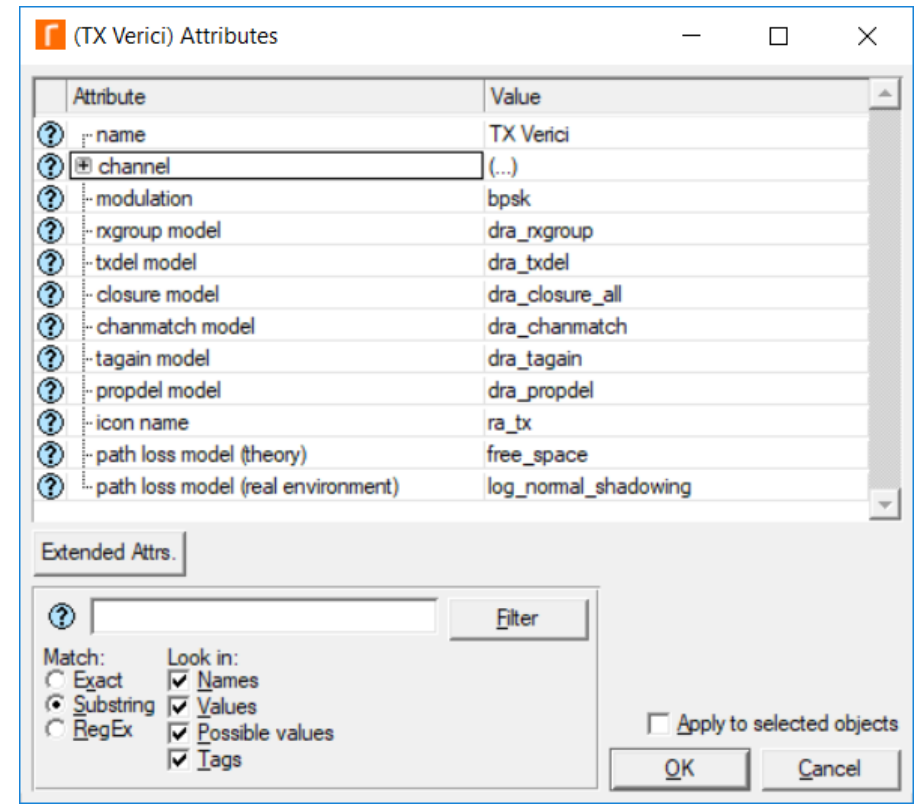

Şekil 8. Benzetim modelinde yol kaybı modeli.

Şekil 8'de, benzetim modelinde yol kaybı modeli seçimi görülmektedir. Hem teoride kullanılan serbest uzay yol kaybı modeli hem de gerçek ortamda karşılaşılan log normal gölgeleme (shadowing) yol kaybı modeli ile benzetim modeli ayrı ayrı çalıştırılmıştır. Büyük ölçekli yayılım modellerinden olan log normal gölgeleme, sinyalin iletildiği ortamdaki nesnelerin yayılım yolunu kapatması sonucunda oluşan yansıma, kırınım, saçılma, vb. sinyal zayıflamalarını karakterize etmek için kullanılmaktadır. Bu durum, log normal gölgelemenin benzetim ortamında gerçek ortamda karşılaşılan sonuçları verdiğini göstermektedir. Serbest uzay yol kaybı ve log normal gölgeleme yol kaybı karşılaştırıldığında, serbest uzay yol kaybında veri kaybının yaşanmadığı görülmektedir. Log normal gölgeleme yol kaybında ise, $100 \mathrm{~dB}$ civarında yol kaybı ve \%13 oranında veri kaybı olmaktadır.

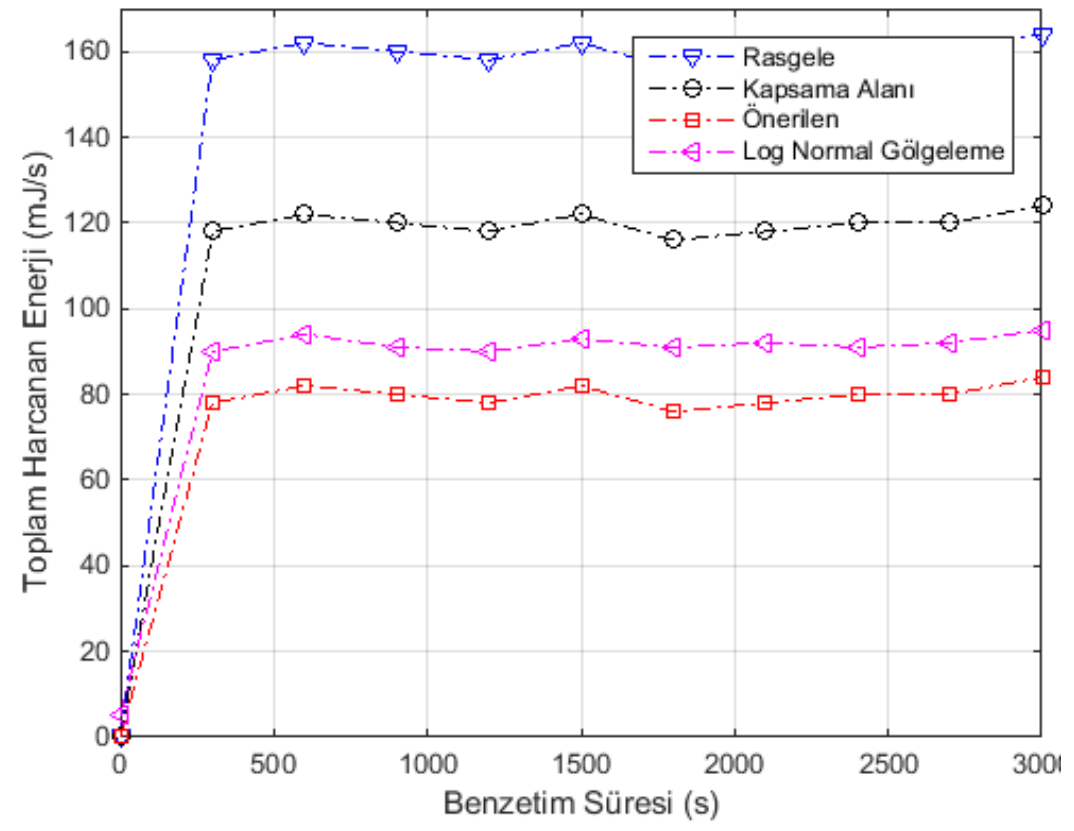

Şekil 9. Toplam harcanan enerji sonuçları. 
Şekil 9'da, benzetim süresine göre toplam harcanan enerjiler görülmektedir. Bu senaryoda, tüm yaklaşımlar için algılayıcı düğüm sayısı 150 ve kapsanacak alan $750 \mathrm{~m}^{2}$ olarak belirlenmiştir. Rasgele yaklaşım, kapsama alanına göre yaklaşım ve önerilen yaklaşım değerleri karşılaştırıldığında, önerilen yaklaşımın en düşük olduğu ve $80 \mathrm{~mJ} / \mathrm{s}$ civarında toplam enerji harcadığı net bir şekilde görülmektedir. Bunun sebebi, önerilen yaklaşımda aynı alanın daha az sayıda algılayıcı düğüm ile sezilmesidir. Toplam harcanan enerji, log normal gölgeleme ile gerçek ortamlar için incelendiğinde paket kayıplarından dolayı toplam enerji tüketiminde \%18 oranında artış yaşanmaktadır.

Tablo 3. Kapsama alanına göre kullanılan algılayıcı düğ̈̈m sayıları.

\begin{tabular}{lcc}
\hline Yaklaşım & $\begin{array}{r}\mathbf{5 0 0} \mathbf{~ m}^{\mathbf{2}} \text { için } \\
\text { düğüm sayıları }\end{array}$ & $\begin{array}{c}\mathbf{7 5 0} \mathbf{~ m}^{\mathbf{2}} \text { için } \\
\text { düğüm sayıları }\end{array}$ \\
\hline Rasgele & 128 & 186 \\
Kapsama alanı & 116 & 174 \\
Önerilen & 100 & 150 \\
\hline
\end{tabular}

Tablo 3’te, belirli bir alana kapsama için gereken toplam düğüm sayıları farklı yaklaşımlar için karşılaştırmalı olarak verilmektedir. Önerilen yaklaşımın, her iki alanın kapsanması için de en az sayıda düğüm gerektirdiği net bir şekilde anlaşılmaktadır.

Tablo 4. Bilgisayarın özellikleri ve yazılım bilgileri.

\begin{tabular}{lc}
\hline Özellik - Bilgi & Değer \\
\hline Bilgisayar dahili bellek (RAM) & $12 \mathrm{~GB}$ \\
Bilgisayar işlemcisi & Intel(R) Core(TM) i7-4700HQ 2.40 GHz \\
Bilgisayar işletim sistemi & Windows 10 Pro x64 \\
Bilgisayar görüntü bağdaştırıcısı & Intel(R) HD Graphics 4600 \\
Bilgisayar harici görüntü bağdaştırıcısı & NVIDIA GeForce GT 750M \\
Yazılım & Riverbed \\
Yazılım versiyonu & 18.7.1 (Build 142 32-bit) \\
Yazılım modülü & Kablosuz haberleşme \\
Yazılım işlemci sayısı & 8 \\
Yazılım işlemci tipi & 586 \\
\hline
\end{tabular}

Tablo 4'te, benzetim modeli gerçekleştirilen bilgisayarın özellikleri ve Riverbed yazılımının bilgileri yer almaktadır. 


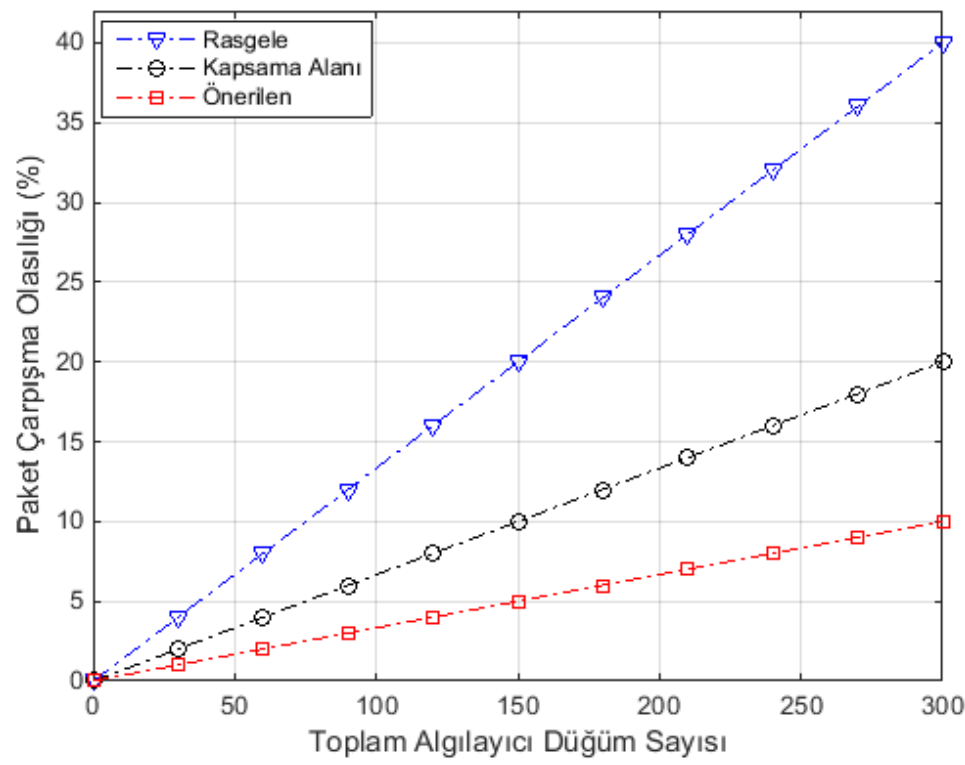

Şekil 10. Paket çarpışma olasılı̆̆ı sonuçları.

Şekil 10'da, toplam algılayıcı düğüm sayısına göre paket çarpışma olasılığı sonuçları görülmektedir. Bu senaryoda, kapsanacak alan $0 \mathrm{~m}^{2}$ ile $1500 \mathrm{~m}^{2}$ arasında değişmekte olup her farklı düğüm sayısı için ayrı ayrı benzetim sonuçları elde edilmiştir. Rasgele yaklaşım, kapsama alanına göre yaklaşım ve önerilen yaklaşım sonuçları karşılaştırıldığında, önerilen yaklaşımın \% 0 - \% 10 aralığı ile en düşük paket çarpışma olasılığına sahip olduğu net bir şekilde anlaşılmaktadır. Bunun nedeni, aynı alanda daha az sayıda düğüm ve dolayısıyla daha az veri trafiği olmasıdır.

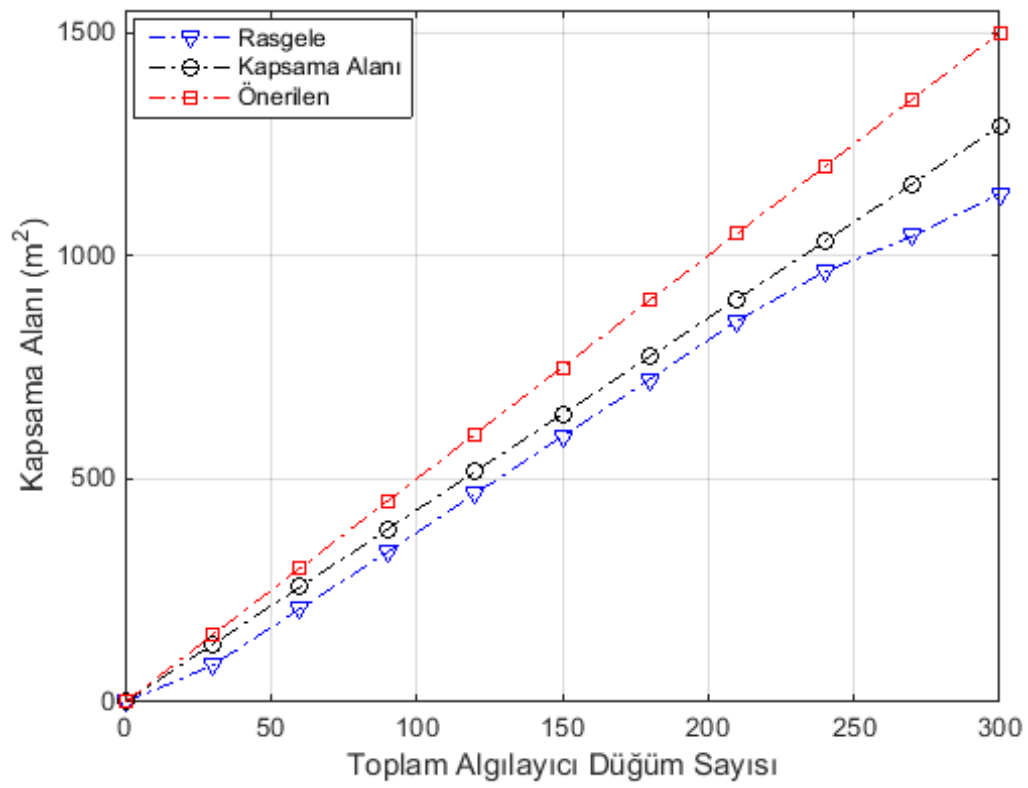

Şekil 11. Kapsama alanı sonuçları.

Şekil 11'de, algılayıcı düğüm sayısına göre kapsama alanı sonuçları görülmektedir. Rasgele yaklaşım, kapsama alanına göre yaklaşım ve önerilen yaklaşım sonuçları karşılaştırıldığında, önerilen yaklaşımın aynı sayıda algılayıcı düğüm ile daha fazla alanı kapsadığı net bir şekilde görülmektedir. Daha az sayıda algılayıcı düğüm 
daha düşük maliyet anlamına geldiğinden dolayı, önerilen yaklaşımın maliyet etkin bir yaklaşım olarak karışımıza çıktığı net bir şekilde anlaşılmaktadır.

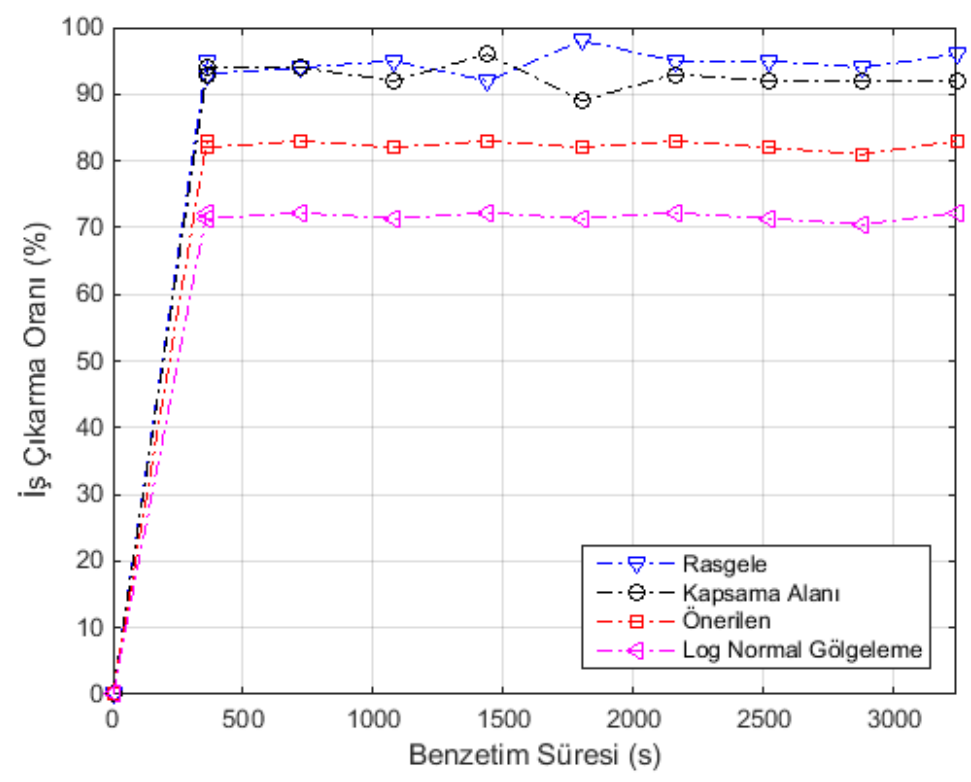

Şekil 12. Kapsama alanı dışındaki kısımların iş çıkarma oranına etkisi.

Şekil 12'de, kapsama alanı dışındaki kısımların iş çıkarma oranına etkisi gösterilmektedir. Şekil incelendiğinde, kapsama alanı dışındaki kısımların iş çıkarma oranını çok büyük oranda etkilemediği anlaşılmaktadır. Önerilen yaklaşımdaki kapsama alanı dışındaki alanların toplam iş çıkarma oranını sadece \%10 gibi düşük bir oranda etkilediği görülmektedir. Buna karşılık, maliyet ve düğüm sayısından büyük tasarruf edilerek önerilen yaklaşımın artıları net bir şekilde gözler önüne serilmektedir. Bununla birlikte, log normal gölgeleme ile gerçek ortam etkisi incelendiğinde iş çıkarma oranında \%13 oranında bir azalma gözlemlenmektedir.

\section{SONUÇLAR}

Bu makale çalışması kapsamında, çok sayıda algılayıcı düğümün büyük bir bölgeye en az maliyetle yerleştirildiği yeni bir yaklaşım önerilmektedir. Düğümlerin ve baz istasyonunun kapsama alanı dikkate alınarak, mümkün olan en az sayıda algılayıcı düğüm ile bir bölgenin sezilmesi amaçlanmaktadır. Kablosuz algılayıcı düğümler; belirli bir alandaki sıcaklık, nem, basınç vb. parametreleri algılamak için tüm alanı kapsayacak şekilde yerleştirilmektedir. Dügümler tarafından sezilen değerler, merkezde sabit olarak bulunan baz istasyonu tarafindan toplanmaktadır. Önerilen kablosuz algılayıcı ağ yaklaşımının benzetim modeli, Riverbed Modeler yazılımı kullanılarak gerçekleştirilmiştir. Önerilen düğüm yerleştirme yaklaşımı yardımıyla, belirli bir alanın en az sayıda kablosuz algılayıcı düğüm ile sezilmesi sağlanmaktadır.

Kablosuz algılayıcı ağlar, günümüzde her alanda yaygın bir şekilde kullanılmaktadır. Bu sebeple, düğüm yerleştirme yaklaşımı ve enerji verimliliği konuları üzerine yoğunlaşan çalışmaların gerçekleştirilmesi gerekmektedir. Düğüm yerleştirme yaklaşımlarıyla ilgili olarak, bu çalışmadan esinlenilerek farklı optimizasyon ve yapay zeka teknikleri kullanılarak yeni yöntemlerin tasarlanması oldukça faydalı olacaktır.

\section{TEŞEKKÜR}

Değerli desteklerinden dolayı kıymetli eşim Sümeyye ve kızım Asel’e çok teşekkür ederim.

\section{KAYNAKLAR}

[1] Tang, J., Hao, B., \& Sen, A. (2006). Relay node placement in large scale wireless sensor networks. Computer Communications, 29(4), 490-501. 
[2] Liu, H., Wan, P. J., \& Jia, X. H. (2006). On optimal placement of relay nodes for reliable connectivity in wireless sensor networks. Journal of Combinatorial Optimization, 11(2), 249-260.

[3] Lloyd, E. L., \& Xue, G. L. (2007). Relay node placement in wireless sensor networks. IEEE Transactions on Computers, 56(1), 134-138.

[4] Ishizuka, M., \& Aida, M. (2007). Stochastic node placement improving fault tolerance in wireless sensor networks. Electronics and Communications in Japan Part I-Communications, 90(3), 42-53.

[5] Younis, M., \& Akkaya, K. (2008). Strategies and techniques for node placement in wireless sensor networks: A survey. Ad Hoc Networks, 6(4), 621-655.

[6] Hu, Y. M., Xue, Y. J., Li, Q., Liu, F. M., Keung, G. Y., \& Li, B. (2009). The sink node placement and performance implication in mobile sensor networks. Mobile Networks \& Applications, 14(2), 230-240.

[7] Pandey, S., Dong, S. Q., Agrawal, P., \& Sivalingam, K. M. (2009). On performance of node placement approaches for hierarchical heterogeneous sensor networks. Mobile Networks \& Applications, 14(4), 401414.

[8] Misra, S., Hong, S. D., Xue, G. L., \& Tang, J. (2010). Constrained relay node placement in wireless sensor networks: Formulation and approximations. IEEE-ACM Transactions on Networking, 18(2), 434-447.

[9] Hou, Y. T., Chen, C. M., \& Jeng, B. (2010). An optimal new-node placement to enhance the coverage of wireless sensor networks. Wireless Networks, 16(4), 1033-1043.

[10] Han, X. F., Cao, X., Lloyd, E. L., \& Shen, C. C. (2010). Fault-tolerant relay node placement in heterogeneous wireless sensor networks. IEEE Transactions on Mobile Computing, 9(5), 643-656.

[11] Lu, K. Z., Chen, G. L., Feng, Y. H., Liu, G., \& Mao, R. (2010). Approximation algorithm for minimizing relay node placement in wireless sensor networks. Science China-Information Sciences, 53(11), 2332-2342.

[12] Liang, W. F., Xu, Y. L., Shi, J. G., \& Luo, J. Z. (2012). Aggregate node placement for maximizing network lifetime in sensor networks. Wireless Communications \& Mobile Computing, 12(3), 219-235.

[13] Lee, S., \& Younis, M. (2012). Optimized relay node placement for connecting disjoint wireless sensor networks. Computer Networks, 56(12), 2788-2804.

[14] Chen, F. C., \& Li, R. L. (2013). Sink node placement strategies for wireless sensor networks. Wireless Personal Communications, 68(2), 303-319.

[15] Tapiador, J. E., \& Clark, J. A. (2013). The placement-configuration problem for intrusion detection nodes in wireless sensor networks. Computers \& Electrical Engineering, 39(7), 2306-2317.

[16] Kimence, S., \& Bekmezci, I. (2014). Weighted relay node placement for wireless sensor network connectivity. Wireless Networks, 20(4), 553-562.

[17] Wu, D. L., Chatzigeorgiou, D., Youcef-Toumi, K., Mekid, S., \& Ben-Mansour, R. (2014). Channel-aware relay node placement in wireless sensor networks for pipeline inspection. IEEE Transactions on Wireless Communications, 13(7), 3510-3523.

[18] Ranga, V., Dave, M., \& Verma, A. K. (2015). Relay node placement to heal partitioned wireless sensor networks. Computers \& Electrical Engineering, 48, 371-388.

[19] Ma, C. F., Liang, W., Zheng, M., \& Sharif, H. (2016). A connectivity-aware approximation algorithm for relay node placement in wireless sensor networks. IEEE Sensors Journal, 16(2), 515-528.

[20] Vikrant, S., Patel, R. B., Bhadauria, H. S., \& Prasad, D. (2016). Policy for planned placement of sensor nodes in large scale wireless sensor network. KSII Transactions on Internet and Information Systems, 10(7), 32133230 . 
[21] Bagaa, M., Chelli, A., Djenouri, D., Taleb, T., Balasingham, I., \& Kansanen, K. (2017). Optimal placement of relay nodes over limited positions in wireless sensor networks. IEEE Transactions on Wireless Communications, 16(4), 2205-2219.

[22] Njoya, A. N., Thron, C., Barry, J., Abdou, W., Tonye, E., Konje, N. S. L., \& Dipanda, A. (2017). Efficient scalable sensor node placement algorithm for fixed target coverage applications of wireless sensor networks. IET Wireless Sensor Systems, 7(2), 44-54.

[23] Chang, C. Y., Chin, Y. T., Chen, C. C., \& Chang, C. T. (2018). Impasse-aware node placement mechanism for wireless sensor networks. IEEE Transactions on Systems Man Cybernetics-Systems, 48(8), 1225-1237.

[24] Cheng, Z., Perillo, M., \& Heinzelman, W. B. (2008). General network lifetime and cost models for evaluating sensor network deployment strategies. IEEE Transactions on Mobile Computing, 7(4), 484-497.

[25] Akyildiz, I. F., Su, W., Sankarasubramaniam, Y., \& Cayirci, E. (2002). Wireless sensor networks: a survey. Computer Networks, 38(4), 393-422.

[26] Vuran, M. C., Akan, Ö. B., \& Akyildiz I. F. (2004). Spatio-temporal correlation: theory and applications for wireless sensor networks. Computer Networks, 45(3), 245-259.

[27] Soman, R., Kudela, P., Balasubramaniam, K., Singh, S. K., \& Malinowski, P. (2019). A study of sensor placement optimization problem for guided wave-based damage detection. Sensors, 19(8), 1-18.

[28] Demetri, S., Picco, G. P., \& Bruzzone L. (2019). LaPS: LiDAR-assisted placement of wireless sensor networks in forests. ACM Transactions on Sensor Networks, 15(2), 1-40.

[29] Nandy, A., Chakraborty, D., \& Shah M. S. (2019). Optimal sensors/actuators placement in smart structure using island model parallel genetic algorithm. International Journal of Computational Methods, 16(6), Special Issue.

[30] Trothe, M. E. S., Shaker, H. R., Jradi, M., \& Arendt K. (2019). Fault isolability analysis and optimal sensor placement for fault diagnosis in smart buildings. Energies, 12(9), 1-12.

[31] Jo, T., Koo, B., Kim, H., Lee, D., \& Yoon J. Y. (2019). Effective sensor placement in a steam reformer using gappy proper orthogonal decomposition. Applied Thermal Engineering, 154, 419-432.

[32] Blachowski, B. (2019). Modal sensitivity based sensor placement for damage identification under sparsity constraint. Periodica Polytechnica-Civil Engineering, 63(2), 432-445.

[33] Spinelli, B., Celis, L. E., \& Thiran P. (2019). A general framework for sensor placement in source localization. IEEE Transactions on Network Science and Engineering, 6(2), 86-102.

[34] Riverbed Modeler, S. S. (2019). Benzetim Yazılımı. San Francisco, USA, https://www.riverbed.com/gb/, (30 Nisan 2019). 